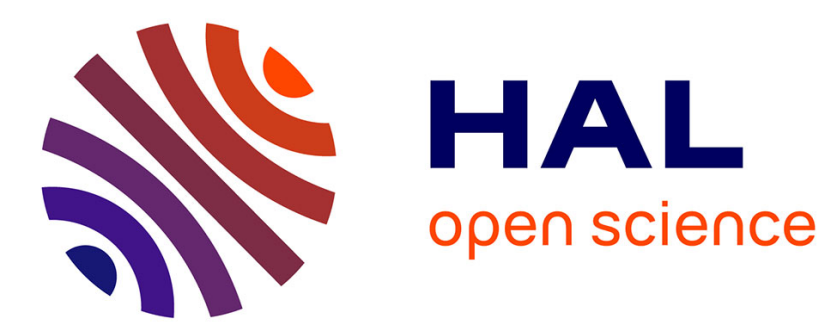

\title{
Localized Technological Change and Efficiency Wages across European Regional Labour Markets
}

Cristiano Antonelli, Francesco Quatraro

\section{To cite this version:}

Cristiano Antonelli, Francesco Quatraro. Localized Technological Change and Efficiency Wages across European Regional Labour Markets. Regional Studies, 2013, 47 (10), pp.1686-1700. 10.1080/00343404.2012.690068 . halshs-00727608

\section{HAL Id: halshs-00727608 \\ https://shs.hal.science/halshs-00727608}

Submitted on 4 Sep 2014

HAL is a multi-disciplinary open access archive for the deposit and dissemination of scientific research documents, whether they are published or not. The documents may come from teaching and research institutions in France or abroad, or from public or private research centers.
L'archive ouverte pluridisciplinaire HAL, est destinée au dépôt et à la diffusion de documents scientifiques de niveau recherche, publiés ou non, émanant des établissements d'enseignement et de recherche français ou étrangers, des laboratoires publics ou privés. 


\title{
Localized Technological Change and Efficiency Wages Across European Regional Labor Markets.
}

\author{
Cristiano Antonelli \\ BRICK (Bureau of Research in Innovation, Complexity Knowledge) \\ Collegio Carlo Alberto \\ Via Real Collegio 30 \\ 10024 Moncalieri (Torino) - Italy \\ Dipartimento di Economia "S. Cognetti de Martiis" \\ Università di Torino \\ Via Po 53 \\ 10124 Torino - Italy
}

and

Francesco Quatraro (corresponding author)

Groupe de Recherche en Droit, Economie et Gestion (GREDEG)

CNRS and University of Nice Sophia Antipolis

250, rue Albert Einstein

06560 Valbonne, France

Tel. +33493954373

Fax: +33493653798

francesco.quatraro@unice.fr.

BRICK (Bureau of Research in Innovation, Complexity, Knowledge)

Collegio Carlo Alberto

Via Real Collegio 30

10024 Moncalieri (Torino) - Italy. 


\begin{abstract}
Internal labour markets and industrial relations in Continental Europe are characterized by substantial rigidity of employed labour engendered by the tight conditions of regional labour markets. This rigidity affects both the rate and the direction of technological change. The increase of wages induces the localized introduction of biased technological change with clear effects on productivity levels. The empirical evidence across a sample of European regions confirms the significant role of the changes in wages both on the increase of the output elasticity of labour and on multi factor productivity.
\end{abstract}

KEY-WORDS: induced approaches; localized technological change; efficiency wages; multi factor productivity growth: regional labor markets.

JEL CODES: O33, R11 


\section{Introduction}

The empirical evidence across Europe shows that substantial changes have been taking place in the direction of technological change in the last decade. Technological change has been far from neutral: actually it exhibits a strong variance across European regions with a bias towards the introduction of labor intensive technologies in core regions characterized by low levels of unemployment and the reverse in peripheral regions with higher levels of unemployment. The analysis of the conditions of European labor markets and more generally the identification of the irreversibility of production factors provides useful insights to understand the rate and the direction of technological change. In Continental Europe labour markets internal to firms are characterized by substantial rigidity: firms face major limitations in the adjustment of employment levels to the changing conditions of both the demand levels and the relative costs of inputs. Such limitations are stronger the lower the levels of unemployment in regional labour markets. As a matter of fact, the conditions of the European labour markets, both external and internal to firms, are such that we can introduce a new stylized fact: both capital and labour, the basic production factors, are rigid as they reflect the high levels of employment in external labor markets. These rigidities affect both the rate and the direction of technological change and account for introduction of new labor intensive technologies induced by the dynamics of wages with strong and positive effects on total factor productivity.

In this paper we aim at elaborating a model of localized technological change (LTC) that builds upon and yet contrasts the induced technological change tradition to analyze the determinants of the direction of technological change and to identify its effects on 
productivity growth. Our results support the idea that LTC is intrinsically biased towards the increased efficiency of the production factor that is becoming relatively more expensive. Specifically, when wages increase, and the irreversibility of production factors localizes and constraints the innovation process in a limited technical space, the direction of technological change is skill-biased.

The empirical evidence of regional labour markets in Continental Europe in the years 1995-2004 stirs our analytical effort because it provides an empirical setting, characterized at the same time by the combination of low levels of unemployment and the strong bargaining power of organized labor, and the fast pace of introduction of LTCs directed towards the intensive use of labor, that can be appreciated in a comparative context.

We therefore articulate an empirical setting linking factor markets' conditions to the dynamics of technological change. In this direction this paper contributes also to the more general debate on the relationships between innovation and employment. The traditional literature on this subject is indeed focused on the analysis of the effects of technological innovation on unemployment, emphasizing the positive impact of innovation, and in particular product innovation, on employment levels (Freeman and Soete, 1987 and 1994; Vivarelli and Pianta, 2000; Piva and Vivarelli, 2005). However, there has been scarce attention to the reverse relationship, i.e. to the effects that labor markets conditions may have on firms' incentives to introduce directed technological change. The articulation of a LTC framework is thus far reaching as it allows for filling this gap and shedding a new light on such complex dynamics. 
The rest of the paper is structured as follows. Paragraph 2 frames the analysis and presents a model of LTC cum efficiency wages. Paragraph 3 provides some descriptive evidence upon the direction of technological change across European regions in the years 1999-2004 and presents the econometric tests of the model elaborated in paragraph 2. The conclusions summarize the main results and put them in perspective.

\section{From the induced technological change hypotheses to the localized technological change approach: the role of labor rigidities and efficiency wages}

The induced technological change approach is back at the centre stage of the economics of technological change, revived by the skill-bias debate that has brought new interest in the bias of technological change as the result of the changes in factor prices (Ruttan, 1997 and 2001). The contributions of Acemoglu (1998 and 2002) have revived recently the analysis of the endogenous generation of directed technological change showing how innovations are aimed at making a more intensive use of human capital inputs that are becoming more abundant.

The LTC framework shares the basic view that the changes in factor costs are the causal factor of the introduction of innovations, yet it articulates a specific variant as it argues that when factor prices change and standard factor substitution is impeded by the substantial irreversibility of inputs, the inducement mechanism can lead to the introduction of technologies with a bias towards the more intensive use of the rigid factors that are becoming more expensive (Atkinson and Stiglitz, 1969; Antonelli, 1995). 
In a context characterized by substantial rigidity of labor inputs the notion of efficiency wages becomes relevant for assessing the rate and the direction of localized technological change. The increase in wages cum labor rigidity in fact impedes the movements on the existing map of isoquants and hence limits the traditional substitution of capital to labor. Firms can cope with the increased levels of wages only if they introduce LTC that makes the existing employment more productive. This outcome is all the more plausible if and when efficiency wages actually enhance the commitment of employees to contribute the innovative efforts of their firms. The tacit competence accumulated by means of learning processes can be valorised and codified. Efficiency wages, in other words, induce more than the solution of organizational failures: they actually induce the introduction of technological changes biased towards higher levels of labor intensity (Akerloff and Yellen, 1986; Shapiro and Stiglitz, 1984).

In view of the arguments elaborated so far, we propose a simple model of LTC, in which innovation efforts stimulated by changes in the relative price of inputs, are not directed to substitute the factors that became more expensive and hence to increase the output elasticity of the other complementary inputs -as in the induced technological change tradition. On the opposite, LTC is characterized by a bias towards the increase of the output elasticity of the rigid factors that are becoming more expensive. Let us start by a general Cobb-Douglas production function, representing the actual technology by means of which regions transform inputs into outputs:

$$
Y_{i t}=A K_{i}^{g} Z_{i t}^{R}
$$


The output produced in region $i$ at time $t$ is a function of the actual levels of capital and labour employed, and of the actual technology signalled by the general efficiency parameter $A$ and by factors' output elasticities. Production factors are available at equilibrium prices defined on factor markets, so that $w$ and $r$ are respectively the unit cost of labour and capital services in region $i$ at time $t$. The solution to the cost minimization problem, after total differentiating equation (1), is given by the well known condition:

$$
\frac{w_{i, t}}{r_{i, t}}=\frac{\beta_{i, t}}{\alpha_{i, t}} \frac{K_{i, t}}{L_{i, t}}
$$

Thus, in equilibrium relative prices must be proportional to the ratio between labour productivity and capital productivity. Let us now assume that a compensated change in factors costs takes place, for example a reduction in the relative price of capital. This in turn translates into an increase (in absolute value) of the slope of the isocost line. The new isocost would define a new equilibrium point that is characterized by a new combination of capital and labour in the production process. In this standard framework, the change in relative prices fully burdens the capital/labour ratio, as the technology is exogenous by definition. The analytical translation of this line of reasoning can be obtained by rearranging the relationship in equation (2) as follows:

$$
\frac{w_{i, t}}{r_{i, t}}=\frac{\overline{\beta_{i}}}{\overline{\alpha_{i}}} \frac{K_{i, t}}{L_{i, t}}
$$


Where the bars over output elasticities signal that they are constant over time. By taking logs of both sides, and then first-differences, we yield the following:

$$
d \log \left(\frac{w}{r}\right) / d t=d \log \left(\frac{\beta}{\alpha}\right) / d t+d \log \left(\frac{K}{L}\right) / d t
$$

In other words, the growth rate of relative prices equals the sum of growth rates of capital intensity and of the ratio between labour and capital output elasticities. However, by definition $d \log \left(\frac{\beta}{\alpha}\right) / d t=0$, and therefore equation (4) boils down to:

$$
d \log \left(\frac{w}{r}\right) / d t=d \log \left(\frac{K}{L}\right) / d t
$$

The main argument of this paper is that changes in relative prices engender directed changes in the production technology, as long as switching costs are relevant and firms are better off by adjusting to new relative prices by reshaping the technology instead of changing the capital/labour ratio. The extreme version of our argument would maintain that firms choose to bear only innovation costs and avoid all factor substitution. This situation is exactly opposite to that represented in Equation (8). When wages increase, firms, in order to remain in the proximity of the original factor intensity, because of the rigidity of labor, have a clear incentive to introduce new technologies and direct them towards a more intensive use of their labor inputs, and hence in increase in $\beta$, that, assuming constant returns to scale, implies a reduction of $\alpha$. 
In this framework firms cannot change neither capital nor labour because of the significant switching costs that make the capital/labour ratio fixed. To hold true the identity in equation (5), the ratio between labour and capital output elasticities must change accordingly.

This amounts to spell out the hypothesis that in contexts where both production factors $K$ and $L$ are irreversible, technological change is induced by changes in relative factor prices and directed towards the modification of the slope of the isoquant through the change of the ratio between output elastiticities $\beta$ and $\alpha$.

From an analytical viewpoint, equation (2) is to be rewritten as follows:

$$
\frac{w_{i, t}}{r_{i, t}}=\frac{\beta_{i, t}}{\alpha_{i, t}} \frac{\overline{K_{i}}}{\overline{L_{i}}}
$$

Where the bars over capital and labour levels signal that they are both necessarily fixed because of irreversibility and switching costs. By taking logs of both sides, and then first-differences, one yields again the relationship in equation (4). However, in this case by definition $d \log \left(\frac{K}{L}\right) / d t=0$, and the equation can be rewritten as follows:

$$
d \log \left(\frac{w}{r}\right) / d t=d \log \left(\frac{\beta}{\alpha}\right) / d t
$$


In this extreme situation, characterized by high levels of factor irreversibility, a change in relative prices induces the localized introduction of biased technological change that affects the ratio between labour and capital output elasticities such that the output elasticity of the production factor that has become more expensive will increase. As a consequence the use of labour is sticky in absolute terms. This results contrasts with the traditional induced technological change approach, where the increase of wages would lead to a reduction in the use of labour. This is fully consistent with the efficiency wages argument and, at least in advanced regions where human capital is becoming the most abundant factor, with the the notion of technological congruence elaborated by Moses Abramovitz and Paul David (1996). The localized technological change hypothesis retains the Hicks-Ruttan assumption according to which technological change is induced by changes in factor markets, but shows that the direction of technological change is exactly the opposite with respect to the induced technological change approach as it is biased in favour of the factor that has become relatively more expensive.

Specifically, if we acknowledge that the rigidity of labor, in internal labor markets, reflects the relative scarcity of labor, in regional labor markets, as measured by low levels of unemployment, we can fully articulate the LTC hypothesis according to which the localized introduction of technological change, stirred by the increase in wages, and supported by the valorization of the tacit competence of incumbent workers, is directed towards the augmentation of the output elasticity of the existing labor inputs that are locally more scarce and hence more rigid so as to favour employment levels. 
The localized introduction of labor-intensive technologies is likely to have much a stronger effect on the multifactor productivity than the induced introduction of capitalintensive technologies because: a) labor biased technological change impinges upon higher intensity of knowledge generation based upon learning processes and the accumulation of competence stirred and sustained by efficiency wages, and a prevalence of product innovations that rely upon higher levels of participation of skilled manpower in non-standardized production processes; b) capital intensive technological change is more likely to reflect the adoption of new vintages of capital goods embodying technological knowledge generated by upstream industries better able to appropriate large shares of productivity enhancing effects (Antonelli and Fassio, 2011; Antonelli and Colombellli, 2011).

In view of the argument elaborated so far, we are now able to spell out the leading working hypotheses underlying the paper.

1) Technological change is far from neutral. Firms are constrained by both static and dynamic irreversibilities within a limited portion of the technical space, in the surrounding of the original technique defined in terms of capital/labour ratio characterizing their production process. In a frictionless world, a compensated change in factor markets conditions would engender a costless adaptation of firms to the new relative prices, by just changing the proportions between capital and labour so as to move upon the original isoquant. However, the acknowledgement of the crucial role of irreversibilities makes it necessary the account for switching costs. 
2) The irreversibility of labour within firms is strictly dependent upon the conditions of local labour markets. In regions characterized by high levels of unemployment, trade unions are weaker and hence much less able to contrast the standard substitution of labour with capital. In such regions the increase of unit wages would induce the introduction of capital-intensive technologies, as in the induced technological change tradition. In regions characterized by full employment, on the opposite, internal and external labour markets are much more rigid and all changes in the levels of employment, at the firm level, bear high levels of switching costs. In these regions firms cannot substitute easily capital to labour. The introduction of LTC biased towards high levels of labour output elasticities becomes the most effective, if not the single, way to cope with the increase in unit wages. In sum, we argue that the levels of employment have a strong positive effect on the working of the inducement mechanism. The levels of employment affect directly and positively the localized introduction of new, more labour intensive technologies, in response to an increase in unit wages.

3) Because of the central role of efficiency wages in the valorization of learning processes, in the consequent generation of technological knowledge and introduction of product innovations, the localized introduction of labor intensive technologies is likely to exert positive effects on the growth of total factor productivity, that are stronger the more abundant is human capital in the region.

\section{Methodology and data}

\subsection{The estimation model and econometric procedures}


In order to grasp the effects of the localized and induced technological change on factors' output elasticities and eventually on productivity, we first need to calculate proxies of relative prices, output elasticities and multi factor productivity (MFP). To this purpose we follow a standard growth accounting approach (Solow, 1957; Jorgenson, 1995; OECD, 2001). Let us start by assuming that the regional economy can be represented by a general Cobb-Douglas production function with constant returns to scale as in Equation (1).

Following Euler's theorem, output elasticities have been calculated (and not estimated) using accounting data, by assuming constant returns to scale and perfect competition in both product and factors markets. The output elasticity of labour has therefore been computed as the factor share in total income:

$$
\begin{aligned}
& \beta_{i, t}=\left(w_{i, t} L_{i, t}\right) / Y_{i, t} \\
& \alpha_{i, t}=1-\beta_{i, t}
\end{aligned}
$$

Where $\mathrm{w}$ is the average wage rate in region $\mathrm{i}$ at time $\mathrm{t}$.

Then the discrete approximation of annual growth rate of MFP in region $i$ at time $t$ is calculated in a traditional way as it follows:

$$
\ln \left(\frac{M F P_{i}(t)}{\operatorname{MFP}_{i}(t-1)}\right) \equiv \ln \left(\frac{Y_{i}(t)}{Y_{i}(t-1)}\right)-(1-\bar{\beta}) \ln \left(\frac{K_{i}(t)}{K_{i}(t-1)}\right)-\bar{\beta} \ln \left(\frac{L_{i}(t)}{L_{i}(t-1)}\right)
$$


Where the bars over output elasticities, following the discrete approximation of the Divisia index, refer to the two years average of both $\alpha$ and $\beta$. In so doing we can appreciate to some extent the effects of the change in output elasticity on the difference between the expected output and the actual one, i.e. the residual (Antonelli and Quatraro, 2010).

Following the hypotheses spelled out in the previous section, we may now propose the structural specification to be estimated in the econometric analysis. The basic hypothesis proposes that a change in relative prices of production factors engenders a change in output elasticities as a consequence of intentional efforts towards the localized introduction of technological change. This leads us to model the growth rate of output elastiticities as a function of relative prices. In addition, it must be stressed that LTC stems from the commitment of resources to innovation activities. Therefore, a proxy for innovation dynamics needs to be inserted in our specification. Finally, because of the relevance of regional labour markets we also consider the effects of unemployment. Indeed, the unemployment rate plays a key role as it shapes the extent to which trade unions may exert their bargaining power so as to make production factors irreversible. Hence, standard textbook macroeconomics suggests that the lower the level of unemployment, the stronger trade unions power. In such a context, if wages increase, firms will be pushed to introduce technological change directed towards a more effective use of labour by increasing its output elasticity $\beta$, and hence reducing $\alpha$. In view of this, our baseline econometric specification is the following:

$$
\ln \left(\frac{\alpha_{i, t}}{\alpha_{i, t-1}}\right)=a+b \ln \alpha_{i, t-1}+c_{1} \ln \left(\frac{w_{i, t-1}}{w_{i, t-2}}\right)+c_{2} \ln \left(\frac{\left(U_{i, t}\right)}{\left(U_{i, t}+E_{i, t}\right)}\right)+\rho_{i}+\sum \psi t+\varepsilon_{i, t}
$$


Where the error term is decomposed in $\rho_{i}$ and $\Sigma \psi t$, which are respectively region and time effects, and the error component $\varepsilon_{i t}$. The growth rate of capital output elasticity $(\alpha)$ is regressed against its lagged level, so as to control for possible mean reversion effects, the growth rate of real unit wages $(w)$, and the unemployment rate $(U / U+E)$ by region $i$. Equation (11) can be estimated using traditional panel data techniques implementing the fixed effect estimator.

Moreover the introduction of a few control variables helps grasping the dynamics of the process. First, the effect of agglomeration economies needs to be accounted for, as it can affect the dynamics of internal factors' markets by influencing the relative supply of labor. We used the traditional proxy present in the literature, i.e. the population density (D) per square kilometres (Quatraro, 2010). Second, the relative regional specialization in manufacturing industries $(S)$ can also affect the results of our estimations because of the different mix of industries (Quatraro, 2009), and therefore needs to be included in the econometric model, which turns out now to be the following:

$$
\begin{aligned}
& 1\left(\mathrm{n} \frac{\alpha_{i, t}}{\alpha_{i, t-1}}\right)=a+b 1 \quad \boldsymbol{\alpha}_{i, t-1}+c_{1} 1\left(\mathrm{n} \frac{w_{i, t-1}}{w_{i, t-2}}\right)+c_{2} 1\left(\mathrm{n} \frac{\left(U_{i, t}\right)}{\left(U_{i, t}+E_{i, t}\right)}\right)+ \\
& +c_{3} 1\left(D_{i, t-1}\right)+c_{4} 1\left(\Phi_{i, t-1}\right)+\rho_{i}+\sum \psi t+\varepsilon_{i, t}
\end{aligned}
$$

The localized introduction of technological change enables efficiency gains with respect to the labour inputs when these become more expensive, and therefore allows for compensating the change in relative prices with a change in the marginal rate of technical substitution between production factors. 
Moreover, in line with the hypothesis 3 spelled out in Section 2, by introducing biased technologies, firms are able to generate fully-fledged technological innovations that also engender an increase in the general efficiency of the production process. The exploitation of learning dynamics and knowledge accumulation stimulated by the dynamics of efficiency wages may indeed engender innovation efforts which are not limited to the production technology, but involve also the organisation and the product portfolio. In view of this, the localized introduction of technological change is likely to exert significant effects on the growth of multi-factor productivity. In order to test this hypothesis we adopt the following econometric specification:

$\ln \left(\frac{M F P_{i, t}}{M F P_{i, t-1}}\right)=z+g \ln \left(M F P_{i, t-1}\right)+h \ln \alpha_{i, t-1}+m \ln T C_{i, t-1}+\rho_{i}+\sum \psi t+\varepsilon_{i, t}$

Where $M F P$ is multifactor productivity, $\alpha$ is capital output elasticity and $T C$ stands for patent applications per thousand workers.

Equations (12) and (13) can be estimated through traditional fixed effect estimators for panel data. However, when analyzing the determinants of TFP growth at the regional level a special focus must be devoted to locational aspects. Regional scientists have indeed showed that geographical proximity may affect correlation between economic variables.

While the traditional econometric approach has mostly neglected this problem, a new body of literature has recently developed, dealing with the identification of estimators 
able to account for both spatial dependence between the relationships between observations and spatial heterogeneity in the empirical model to be estimated. Former treatment of spatial econometric issues can be found in Anselin (1988), subsequently extended by Le Sage (1999).

The idea behind the concept of spatial dependence is straightforward. The properties of economic and social activities of an observed individual are likely to influence economic and social activities of neighbour individuals. Formally this relationship can be expressed as follows:

$$
y_{i, t}=h\left(y_{j, t}\right), i=1, \ldots, n, j \neq i
$$

The dependence can therefore be among several observations. If this is the case, structural forms like equation (12) are likely to produce a bias in the estimation results. There are different ways to cope with this issue. First, one may apply spatial filters to the sample data, so as to remove the spatial structure and then apply traditional estimation techniques. Second, the relationship can be reframed using a spatial error model (SEM), in which the error term is further decomposed so as to include a spatial autocorrelation coefficient. Third, one may apply the spatial autoregressive model (SAR), which consists of including the spatially lagged dependent variable in the structural equation.

We decided to compare the SAR and SEM models in order to have a direct assessment of the spatial dependence of productivity growth between close regions. However, most of the existing literature on spatial econometrics propose estimator appropriate for 
cross-sectional data. Given the panel data structure of our sample, we therefore follow Elhorst (2003) extending Equation (12) so as to obtain the SAR (Eq. 15) and the SEM (Eq. 16) specifications:

$$
\begin{aligned}
& \ln \left(\frac{\alpha_{i, t}}{\alpha_{i, t-1}}\right)=\xi H \ln \left(\frac{\alpha_{i, t}}{\alpha_{i, t-1}}\right)+b \ln \alpha_{i, t-1}+c X_{i, t-1}+\rho_{i}+\sum \psi t+\varepsilon_{i, t} \\
& \ln \left(\frac{\alpha_{i, t}}{\alpha_{i, t-1}}\right)=b \ln \alpha_{i, t-1}+c X_{i, t-1}+\rho_{i}+\sum \psi t+\varepsilon_{i, t}+\phi_{t} \\
& \phi_{t}=\delta H \phi_{t}+\mu, E\left(\mu_{t}\right)=0, E\left(\mu_{t} \mu_{t}^{\prime}\right)=\sigma^{2} I_{N}
\end{aligned}
$$

We also extend Equation (13) so as to obtain the SAR (Eq. 17) and the SEM (Eq. 18) specifications:

$$
\begin{aligned}
& \ln \left(\frac{M F P_{i, t}}{M F P_{i, t-1}}\right)=\psi H \ln \left(\frac{M F P_{i, t}}{M F P_{i, t-1}}\right)+d \ln M F P_{i, t-1}+e Z_{i, t-1}+\rho_{i}+\sum \psi t+\varepsilon_{i, t} \\
& \ln \left(\frac{M F P_{i, t}}{M F P_{i, t-1}}\right)=b \ln M F P_{i, t-1}+e Z_{i, t-1}+\rho_{i}+\sum \psi t+\varepsilon_{i, t}+\phi_{t}
\end{aligned}
$$

$$
\not=\Phi \not p+\mu_{t} E\left(\mu_{t}\right)=0, E\left(\mu_{t} \mu_{t}^{\prime}\right)=\sigma^{2} I_{N}
$$

Where $X$ and $Z$ are the vectors of regressors, $\xi$ and $\psi$ are referred to as spatially autoregressive coefficients, $\phi$ is the spatial component of the error model and $H$ is a 
weighting matrix. This latter can be defined either as a contiguity or as a normalized distance matrix. In the analysis that follows we chose the second alternative, by building a symmetric matrix reporting the distance in kilometres among the city centre of the regional chief towns.

\subsection{The data}

In order to investigate the relationships between changes in factor markets, directed technological change and MFP, we have drawn data from the Eurostat regional statistics, which gathers together statistical information regarding European regions since 1995. Due to data constraints, we focus our econometric exercise on a balanced sample of NUTS II regions across different European Countries, i.e. Austria, Belgium, Germany, Spain, Finland, France, Italy, Hungary, Poland and UK over the period 2000$2004^{1}$.

For what concerns the calculation of the MFP index, we needed output, labour and capital services, and the labour and capital shares. As a measure of output $\left(Y_{i t}\right)$ we used the real GDP (2000 constant prices). Eurostat also provides with estimation of capital stock $\left(K_{i t}\right)$ and employment, although it does not provide data about hours worked at the regional level. For this reason we used average hours worked at the country level provided by the Groningen Growth and Development Centre (www.ggdc.net), and then calculate total hours worked $\left(L_{i t}\right)$. Although this does not allow us to appreciate crossregional difference in average hours worked, nonetheless it allows us to account at least for cross-country differences. The labour share $\left(\beta_{i t}\right)$ is calculated using data on the 
compensation of employees and the GDP according to equation (8), while capital output elasticity has then been calculated following equation (9).

The data about the unemployment rates across European regions, as well as those concerning population density, the total regional value added and the regional value added in manufacturing industries have been drawn by the Eurostat regional statistics.

For what concerns the role of formalized innovation efforts in the localized introduction of technological change, we decided to use patent applications to European Patent Office (EPO) as proxies of regional innovative activities. The time series provided by the EPO start in 1978, and assign patents to regions according to inventors' addresses. The limits of patent statistics as indicators of innovation activities are well known. The main drawbacks can be summarized in their sector-specificity, the existence of non patentable innovations and the fact that they are not the only protecting tool. Moreover the propensity to patent tends to vary over time as a function of the cost of patenting, and it is more likely to feature large firms (Pavitt, 1985; Levin et al., 1987; Griliches, 1990).

Nevertheless, previous studies highlighted the usefulness of patents as measures of production of new knowledge, above all in the context of analyses of innovation performances at the aggregate regional level (Acs et al., 2002). Besides the debate about patents as an output rather than an input of innovation activities, empirical analyses showed that patents and $\mathrm{R} \& \mathrm{D}$ are dominated by a contemporaneous relationship, providing further support to the use of patents as a good proxy of innovation (Hall et al., 
1986). In table 1 we report the correlation matrix for the variables considered in our empirical estimations.

\section{INSERT TABLE 1 ABOUT HERE}

The figures of Table 1 show that, on the whole, the pairwise correlations across regressors are generally low, casting away any concern of multicollinearity. There is only a relative high coefficient for what concerns the relationship between $D$ and $S$. This would suggest to separately chek for their effects on the growth rate of $\alpha$.

Figures 2 to 4 provide us with a preliminary statistical description concerning both the distribution of regions across different values of capital output elasticity, and the change of such distribution over time.

\section{INSERT FIGURE 1 ABOUT HERE}

Figure 2 shows the kernel density estimation for the distribution of sampled regions over capital output elasticity for two periods. The continuous line refers to the period 1995-2003, while the dashed line refers to the period 2000-2003. This evidence conveys important information. First of all, there is a wide dispersion of regions across different levels of capital elasticities. These are far from homogeneous, and both the distributions show the existence of more than one peak. Moreover, and more importantly, the distribution changes over time. The shape of dashed line appears to be fairly different from that the continuous line. This means that overall the output elasticity of capital 
changed over time. The prominent peak around 0.6 suggests that on average, the capital share in national income increased in the early 2000 s, with respect to the second half of the 1990s.

\section{INSERT FIGURE 2 ABOUT HERE}

Figure 3 shows the distribution of sampled regions across capital output elasticities ${ }^{2}$. It is evident that the range of variation is quite large, falling in the interval $[0.372,0.758]$. The darkest areas are those characterized by the highest values of alpha. Regions belonging to this group can be found in Northern Italy, in Greece, mainly in Poland and in Southern Portugal. The dark grey areas are at a lower level of output elasticity, but still quite significant. Most of Eastern Europe regions can be found in this class, along with Central and Southern Italy and central Spain. The median class, roughly centred on 0.5, comprises some Spanish and French regions, as well as all Austrian regions and a few ones from Southern Germany. The two lowermost classes finally include the core regions such as all the UK regions, Northern France and the bulk of German regions.

A sharp partition emerges from this picture. North European regions appear indeed to be characterized on average by fairly low levels of capital output elasticity, and hence by high levels of labour output elasticity. This supposedly reflects the employment conditions of the regional labour markets that make it convenient to direct localized technological changes towards the introduction of labour-augmenting innovations. This is likely to be related, above all in the case of France, UK and Norway, to the actual change in industrial structure, characterized by the increasing weight of service sectors and the increasing supply of qualified work. On the contrary, in peripheral Southern 
regions, the persistent specialization in traditional manufacturing industries and higher levels of unemployment with the consequent lower bargaining power of trade-unions and hence lower levels of rigidity in internal labor markets and factor irreversibility, favour the working of the traditional induced technological change mechanisms so as to make capital output elasticity higher than that of labour.

\section{INSERT FIGURE 3 ABOUT HERE}

Figure 4 shows the dispersion of capital output elasticity over time for each region. Also in this case, darker regions are those in which the variation over time is higher. The highest variance can be found in Greece, while lower levels are observed in Easter Europe regions, Portugal, Corsica and Campania. Some degree of variation can also be observed in Italian, French and UK regions, while most of German and Spanish regions are characterize by basically stable output elasticities over time. It is worth stressing that the quite heterogeneous picture resulting from this descriptive exploration reveals that time stability of output elastiticities, and therefore parallel shifts of the production function, is possible but not necessary. On the contrary, different regions may also be characterized by higher or lower variation of output elasticities.

\section{Econometric results: determinants and effects of LTC}

In this Section we provide the results for the econometric estimations. Table 2 reports the fixed effect estimations of equation (12). This aims at assessing the effects of changes of factor costs on factors' output elasticity, so as to test the first and main hypothesis concerning the localized inducement of technological change. In column (1) 
one can find the baseline model, wherein the growth rate of capital output elasticity $(\alpha)$ is regressed against the growth rate of unit labour cost and the unemployment rate, while the lagged value of $\alpha$ is meant to capture possible mean reversion effects. Our main hypothesis proposes that due to static and dynamic irreversibilities, firms respond to changes in factor costs by introducing technological innovations to increase the effectiveness of the production factor that is more rigid and has become relatively more expensive, so as to adapt the marginal rate of technical substitution between factors accordingly. Specifically, when unit wages increase, because of irreversibility of both capital and labour, positively associated with levels of unemployment in regional labour markets, firms are induced to introduce LTC directed towards a more effective use of labour.

Therefore, if wages increase, in a context shaped by low levels of unemployment, labour output elasticity is expected to increase and hence, assuming constant returns to scale, capital output elasticity to fall. The results in column (1) are fully in line with this proposition. The coefficients of the growth rate of wages and unemployment are indeed both significant, being the former negative and the latter positive.

Column (2) shows the result of the estimation of the baseline enriched by the inclusion of the effects of agglomeration economies, proxied by the population density per square kilometres. It interesting to note that this new regressor does not turn to be significant, and it does not affect the significance of our main variables, i.e. the growth rate of unit wages and the unemployment rate, which keep being respectively negative and positive. 
In column (3) we also added the manufacturing specialization index, to mitigate the possible bias that the specialization in of mature and capital intensive activities might introduce in our estimates. Even in this case, the additional control variable did not change the substance of the results.

Finally, column (4) presents the results for the fully specified model. The coefficient for the growth rate of unit wages confirms to be negative and statistically significant, while the one for the unemployment rate keeps being positive and significant. Once again, the coefficients for the control variables are not significant. All in all, it may be concluded that the results about both the inducement mechanisms engendered by the change in relative prices and the key role of unemployment are quite robust and persistent across different econometric specifications. The higher the level of unemployment, the lower the power of trade unions, which make it less problematic for firms to make a more intensive use of capital if wages increase, with a given technology. On the contrary, in regional contexts characterized by low levels of unemployment, trade unions are able to introduce a degree of rigidity such that firms may be better off only by increasing the effectiveness of (the irreversible stock of internal) labour.

\section{INSERT TABLE 2 ABOUT HERE}

We noted in the previous Section that the analysis of such phenomena at the regional levels may be significantly affected by the spatial structure of the data. For this reason we proposed to check for the robustness of our results by implementing two different estimation techniques, i.e. the SEM and the SAR model. 
Table 3 shows the results for the SEM model (Equation (16)). The first column presents the baseline specification of the model, including the growth rate of wages and patents as well as the unemployment rate. Once again, the growth rate of wages shows a negative and significant coefficient, which is robust across all the four specifications. The same applies to the coefficient of the unemployment rate, which is positive and significant across all the specifications. As expected, the decomposition of the error term to account for spatial dynamics engendered an increase in the share of variance explained by the model.

\section{$>>>$ INSERT TABLE 3 ABOUT HERE $<<<$}

Fairly similar evidence is provided by table 4, where the results of the SAR estimations (Equation (15)) are reported. The negative and significant effects of wages growth rates are persistent across all the specifications. The unemployment rate keeps showing a positive and significant effect on the growth rate of capital output elasticity in all the specification but the one presented in column (1). On the whole, the unemployment rate seems to be the variable that was most affected by the inclusion of the spatially lagged dependent variable in the structural form. Interestingly enough, the spatial lag of the dependent variable shows a negative and highly significant coefficient across all the different specifications. This evidence opens up interesting avenues for further research, which goes however beyond the scope of the present paper. It would suggest indeed that the explicit account for spatial dynamics of capital output elasticities can absorb the impact of unemployment rates. In other words, one could think about the effects of labour mobility across neighbour regions, and maintain that the introduction of LTC in 
a specific area is affected by the relative rather than absolute conditions of local labour markets.

\section{$>>>$ INSERT TABLE 4 ABOUT HERE $<<<$}

So far, empirical results have provided support to the hypotheses that changes in wages are likely to affect the dynamics of capital output elasticities, i.e. they engender the introduction of LTC. This is all the more important when the unemployment rates increase. The investigation of spatial dependence called for a more articulated view upon the role of unemployment and of the rate of technological change, taking into account the interactive dynamics with neighbour regions.

However, we also argued that the introduction of localized technological change engendered by the dynamics of efficiency wages in contexts characterized by factors rigidity is also likely to exert strong positive effects on the productivity growth. Efficiency wages indeed are likely to enhance the commitment of employment, creating the conditions for augmented learning-by-doing mechanisms and setting in motion a process of deeper knowledge accumulation which benefits the general efficiency of the production process, due both to organisational improvements and to the renewal of the product portfolio. For this reason we turn now to investigate the relationships between the introduction of LTC and the dynamics of productivity growth. Table 5 presents the results of the fixed estimation of Equation (13).

The MPF growth rate is regressed against the lagged value of MFP level as well as the lagged value of capital output elasticity, in column (1). As expected, the lagged 
dependent variable shows a positive and significant coefficient. This suggests that a $\beta$ convergence process features sampled regions (even though it is not a sufficient condition for this conclusion). The output elasticity of capital also yields a negative effect on productivity. This means that an increase in the effectiveness of labour, which follows the increase in its relative price, is likely to yield general efficiency gains in the production process. The dynamics of multifactor productivity are therefore shaped by the introduction of LTC. This result persistent even when the level of innovation efforts are introduced in the model, like in column (2). The sign of the coefficient on $\alpha$ is indeed negative and significant again, while $T C$ (our proxy for the intensity of technological efforts based on patents) shows a positive and significant coefficient. This result allows us to conclude that systematic innovation efforts biased towards higher levels of labor intensity have a positive effect on the growth of MFP.

\section{INSERT TABLE 5 ABOUT HERE}

In columns (3) we substitute the labour unit cost for capital output elasticity as a regressor. Following the previous estimations, we should expect the dynamics of wages to be positively related to productivity via the mechanisms of LTC. The results are definitely coherent with the proposed framework, supporting the idea that the dynamics of factor costs are likely to affect productivity dynamics through the introduction of LTC $^{3}$. These results can be considered an important test of the positive effects of the mechanisms engendered by efficiency wages upon the efficiency of the production process. Such result is also persistent to the inclusion of innovation efforts (TC) in the picture (column (4), which in turns shows a positive and significant coefficient. 
However, the issue of spatial dependence is particularly relevant when the dynamics of regional productivity growth are at stake. For this reason we present the estimations of the SEM and SAR models in tables 6 and 7. The results are quite in line with those showed in table 5 .

\section{$>>$ INSERT TABLES 6 AND 7 ABOUT HERE $<<<$}

The coefficient on the output elasiticity of capital is negative and significant, suggesting that the decrease in the relative efficiency of capital, and hence an increase in the relative efficiency of labour, engenders an increase in the general efficiency of the production process. Moreover, the substitution of the wage rate for capital output elasticitiy also yields the expected results, providing further support to the hypotheses that the introduction of LTC stemming from the dynamic of relative factor prices is likely to significantly affect the growth of multi-factor productivity.

\section{Conclusions}

Internal labour markets and industrial relations reflect the conditions of local factor markets and specifically the levels of regional unemployment. In regions with low levels of unemployment, trade unions have much a stronger bargaining power with clear effects in terms of both increase of wages and substantial rigidity of employed labour that affect the rate and the direction of technological change. Both induce LTC directed towards the more intensive use of labor inputs that are becoming more expensive and yet cannot be dismissed. 
When local labor markets are characterized by relative scarcity, hence high wages and low levels of unemployment, and internal labor markets are characterized by strong bargaining power of trade-unions, firms cannot fire their workers and substitute capital to labor when wages increase. The rigidity of labor adds to the rigidity of capital, hence firms are localized in a tiny technical region by the quasi irreversibility of both production factors. This marks a clear difference with respect to the traditional induced technological change, where changes in relative prices engender the adoption of new technologies aimed at saving the use of the production factor that has become more expensive. Here the stickiness of production factors do not allow firms to modify the amount of labour employed in the production process. Changes in wages therefore push them to look for technological solutions enhancing the output elasticity of labour. The ultimate result, given the rigidity of factors markets, is an increase of the output produced.

At the same time firms are localized in a limited portion of the space of techniques by their limited knowledge and competence based upon learning processes that root their technological knowledge in a technical region that is close to their current factor intensity. Hence they cannot move along existing isoquants when the relative prices of inputs change. They prefer to try and innovate so as to introduce a new and superior technology that makes it possible to reconcile the marginal productivity of labor with the increased wages and is as close as possible to the existing one so as to reduce the amount of switching. This leads to the introduction of new localized and biased technologies that are directed towards the more intensive use of the existing production factors that are becoming more expensive. On the opposite, when unemployment levels are high and the bargaining power of trade unions is lower, the increase of wages is 
more likely to induce the introduction of labor-saving technological changes, as in the induced technological change tradition.

Our argument can be considered a direct application of the efficiency wages hypothesis. Strong labour unions are not only able to obtain an increase in wages and to rule out the substitution of capital to labour, but also to increase the commitment and dedication of labor force in the valorization of internal competence based upon learning by doing. Firms pushed to pay wages in excess of short-term productivity levels to their irreversible levels of incumbent employment are induced to rely upon the enhanced generation of technological knowledge that relies upon qualified learning processes so as to try and match the twin constraint of their labor force with the introduction of new labor-intensive technologies that enable to increase their productivity. The reliance upon internal learning processes sustained by efficiency wages leads to an increase of MFP levels. Such a process is the result of an out-of-equilibrium context of action where the search for new technologies is induced by out-if-equilibrium conditions and engenders further out-of-equilibrium conditions.

The evidence gathered confirms that technological change across the European regions in the period we considered has been strongly biased and uneven. Technological change was neutral only in a large minority of cases. The introduction of new technologies has affected the output elasticity of production factors. This is the first and most important result of the analysis carried out in this paper: for quite along time standard economics in fact assumed the neutrality of technological change. 
The econometric evidence confirms that the localized inducement mechanism in Europe has pushed firms facing a substantial increase in wage levels to introduce new localized technologies directed towards the more intensive usage of labor. The working of regional labour markets exerts a strong and significant effect on the direction and intensity of the localized introduction of new technologies in response to the increase of unit wages. The analysis of total factor productivity enables to grasp the strong and positive effects of the localized introduction of biased and directed technologies on the general efficiency of the production process.

The understanding of the economic complexity of technological change enables to grasp the dynamics of the iterative interplay between the determinants and the effects of LTC. A double loop in fact is likely to take place. High levels of employment are at the origin of increasing unit wages. Firms however can substitute capital to labour only in regions with high levels of unemployment. In regions with high levels of employment, instead, firms can cope with the increase of unit wages only the localized introduction of new technologies that make a more effective use of the existing labour inputs. The successful introduction of such new technologies is likely to reduce further the levels of unemployment in regional labour markets and hence to push towards the additional increase of unit wages. A self-reinforcing process is clearly at work with important dynamics effects that confirm that innovation is an emerging property of a typical system dynamics. 
ACKNOWLEDGMENTS. We acknowledge the funding of the European Union Directorate for Research, with the Grant number 266959 to the research project 'Policy Incentives for the Creation of Knowledge: Methods and Evidence' (PICK-ME), within the context Cooperation Program / Theme 8 / Socio-economic Sciences and Humanities (SSH) and of the Collegio Carlo Alberto with the project IPER and the support of the GREDEG, University of Nice. We wish to thank Stefano Breschi as well as the two anonymous referees for their useful comments. Authorship is alphabetical and for the purposes of assessment of responsibility, each author contributes equally to the paper. 


\section{NOTES}

\footnotetext{
${ }^{1}$ We acknowledge that the use of administrative regions to investigate represents only an approximation of the local dynamics underpinning economic activities. Indeed administrative borders are arbitrary, and therefore might not be representative of the spontaneous emergence of local interactions. It would be much better to investigate these dynamics by focusing on local systems of innovation. However, it is impossible to find out data at such a level of aggregation. Moreover, the identification of local systems involve the choice of indicators and threshold values according to which one can decide whether to unbundle or not local institutions. This choice is in turn arbitrary, and therefore it would not solve the problem, but it would only reproduce the issue at a different level. Thus we think that despite the unavoidable approximation, our analysis may provide useful information on the dynamics under scrutiny.

${ }^{2}$ It must be noted that for the sake of completeness, the descriptive analysis provided in this Section includes also the evidence for the UK, though such data are then not used in the econometric test discussed in Section 4.

${ }^{3}$ It is worth noting that when including in the same regression the unit labour cost and innovation levels, the latter variable is likely to fully explain the variance in the dependent variable. In our framework innovation levels are indeed strongly related, and wages have an effect on productivity only through localized innovation efforts.
} 


\section{References}

ABRAMOVITZ, M. AND DAVID, P. A. (1996), Convergence and delayed catch-Up: Productivity leadership and the waning of American exceptionalism, in R. Landau, T., Taylor and G. Wright (eds.), The mosaic of economic growth. Stanford: Stanford University Press, 21- 62.

ACEMOGLU, D. (1998), Why do new technologies complement skills? Directed technological change and wage inequality, Quarterly Journal of Economics, $113,1055-1089$.

ACEMOGLU, D. (2002), Directed technological change, Review of Economic Studies 69, 781-809.

ACS, Z.J., ANSELIN, L. AND VARGA, A. (2002) Patents and innovation counts as measures of regional production of new knowledge, Research Policy, 31, 10691085.

AKERLOFF, G.A. AND YELLEN, J.L. (1986), Efficiency wages models and the labor market, Cambridge University Press, Cambridge.

ANTONELLI, C. (1995), Localized technological change and industrial dynamics, Amsterdam, Kluwer.

ANTONELLI, C. AND QUATRARO, F. (2010), The effects of biased technological change on total factor productivity. Empirical evidence from a sample of OECD countries, Journal of Technology Transfer, 35, 361-383.

ANTONELLI, C., FASSIO, C. (2011), Globalization and innovation in advanced economies, in Libecap, G. (ed.) Advances in the study of entrepreneurship, innovation and economic growth. Volume 22 Emerald Publishing, Cambridge. 
ANTONELLI, C., COLOMBELLI, A. (2011), Globalization and directed technological change at the firm level. The European evidence, in Libecap, G. (ed.) Advances in the study of entrepreneurship, innovation and economic growth. Volume 22 Emerald Publishing, Cambridge,.

ATKINSON, A. B. AND STIGLITZ, J.E. (1969), A new view of technological change, Economic Journal 79, 573-578.

ELHORST, P. J. (2003), Specification and estimation of spatial panel data models. International Regional Science Review 26, 244-268.

FREEMAN, C. AND SOETE, L. (eds) (1987), Technical change and full employment, Oxford, Basil Blackwell.

FREEMAN, C. AND SOETE, L. (1994), Work for all or mass unemployment? Computerised technical change into the Twenty-first Century, London-New York, Pinter.

GRILICHES, Z. (1990), Patent statistics as economic indicators: A survey, Journal of Economic Literature, 28, 1661-1707.

GRONINGEN GROWTH AND DEVELOPMENT CENTRE, (2010), Total Economy Database, http://www.conference-board.org/data/economydatabase/.

JORGENSON, D.W. (1995), Productivity Volume 1: Post-war US economic growth, Cambridge, MA, MIT Press.

LE SAGE, J.P. (1999), The theory and practice of spatial econometrics, Department of Economics, University of Toledo, available at www.spatial-econometrics.org.

LEVIN, A., LIN, C., CHU, C. (2002), Unit root tests in panel data: Asymptotic and finite-sample properties, Journal of Econometrics, 108, 1-24.

OECD, (2001), Measuring productivity. Measurement of aggregate and industry-level productivity growth, Paris. 
PAVITT, K. (1985), Patent statistics as indicators of innovative activities. Possibilities and problems, Scientometrics, 7, 77-99.

PIVA, M. AND VIVARELLI, M. (2005), Innovation and Employment: Evidence from Italian Microdata, Journal of Economics, 86, 65-83.

QUATRARO, F. (2010), Knowledge coherence, variety and productivity growth: Manufacturing evidence from Italian regions, Research Policy, 2010, 39, 12891302.

QUATRARO, F. (2009), Innovation, structural change and productivity growth. Evidence from Italian regions, 1980-2003, Cambridge Journal of Economics, 33, 1001-1022.

RUTTAN, V.W. (2001), Technology growth and development. An induced innovation perspective, Oxford, Oxford University Press.

RUTTAN, V. W. (1997), Induced innovation, evolutionary theory and path dependence: Sources of technical change, Economic Journal, 107, 1520-1529.

SHAPIRO, C. AND STIGLITZ, J. E. (1984), Equilibrium unemployment as a worker discipline device, American Economic Review 74, 433-44.

SOLOW R. M. (1957), Technical change and the aggregate production function, The Review of Economics and Statistics 39, 312-320.

VIVARELLI, M. AND PIANTA, M. (eds) (2000), The employment impact of innovation: Evidence and policy, London, Routledge. 
Figure 1 - Kernel density estimation for capital output elasticity

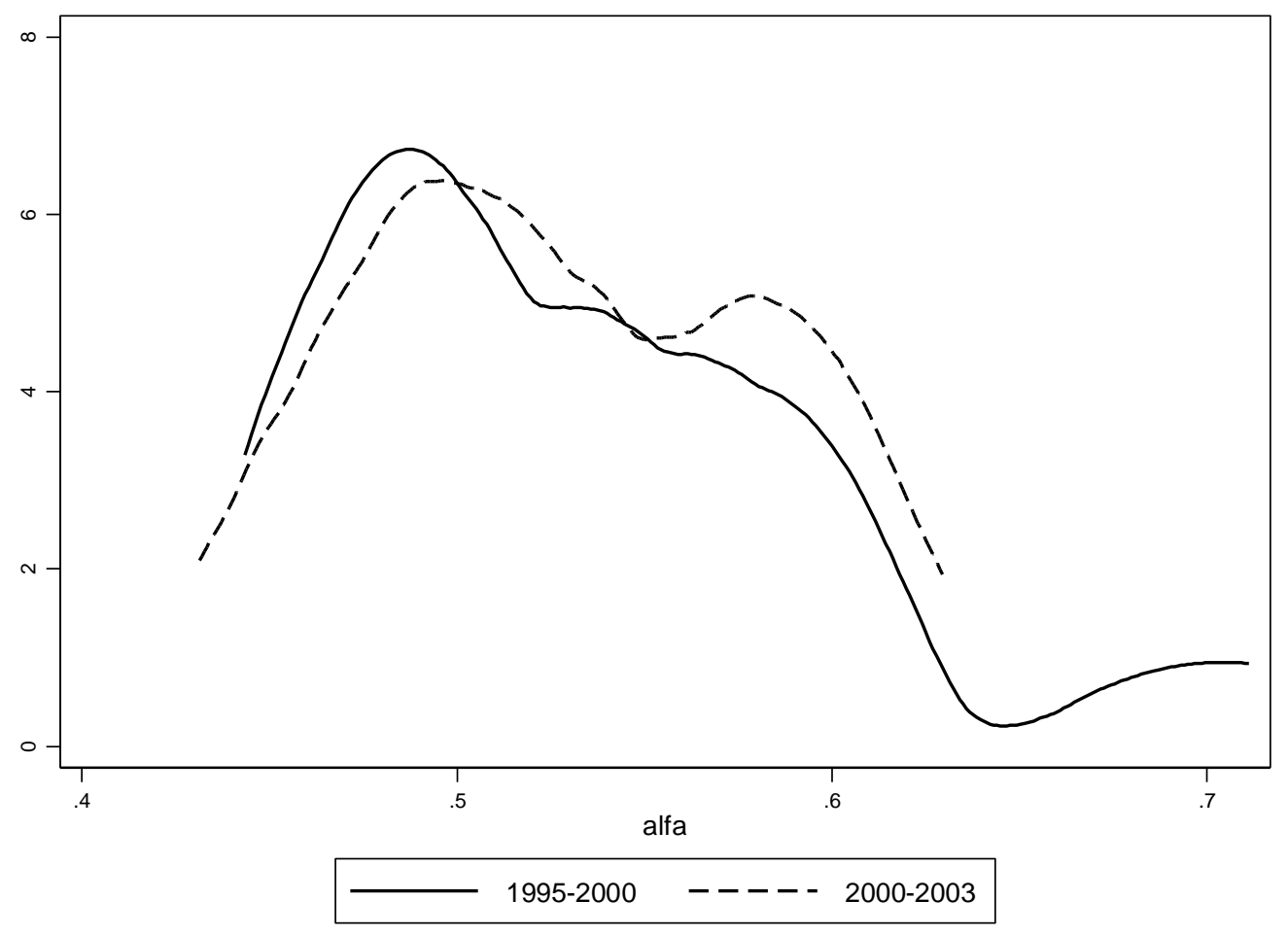


Figure 2 - Average levels of alpha, by region

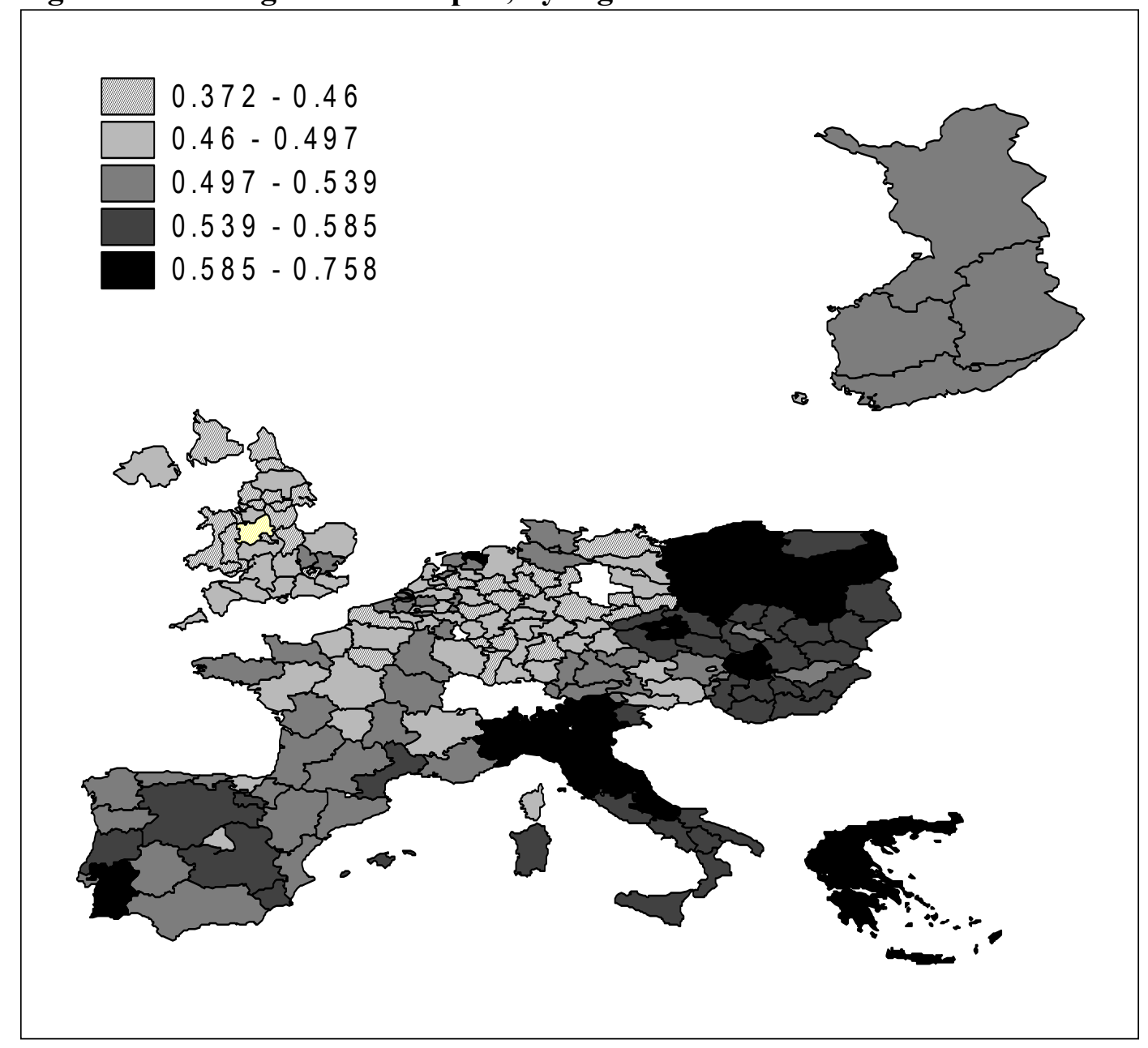


Figure 3 -Time dispersion of alpha (standard deviation), by region

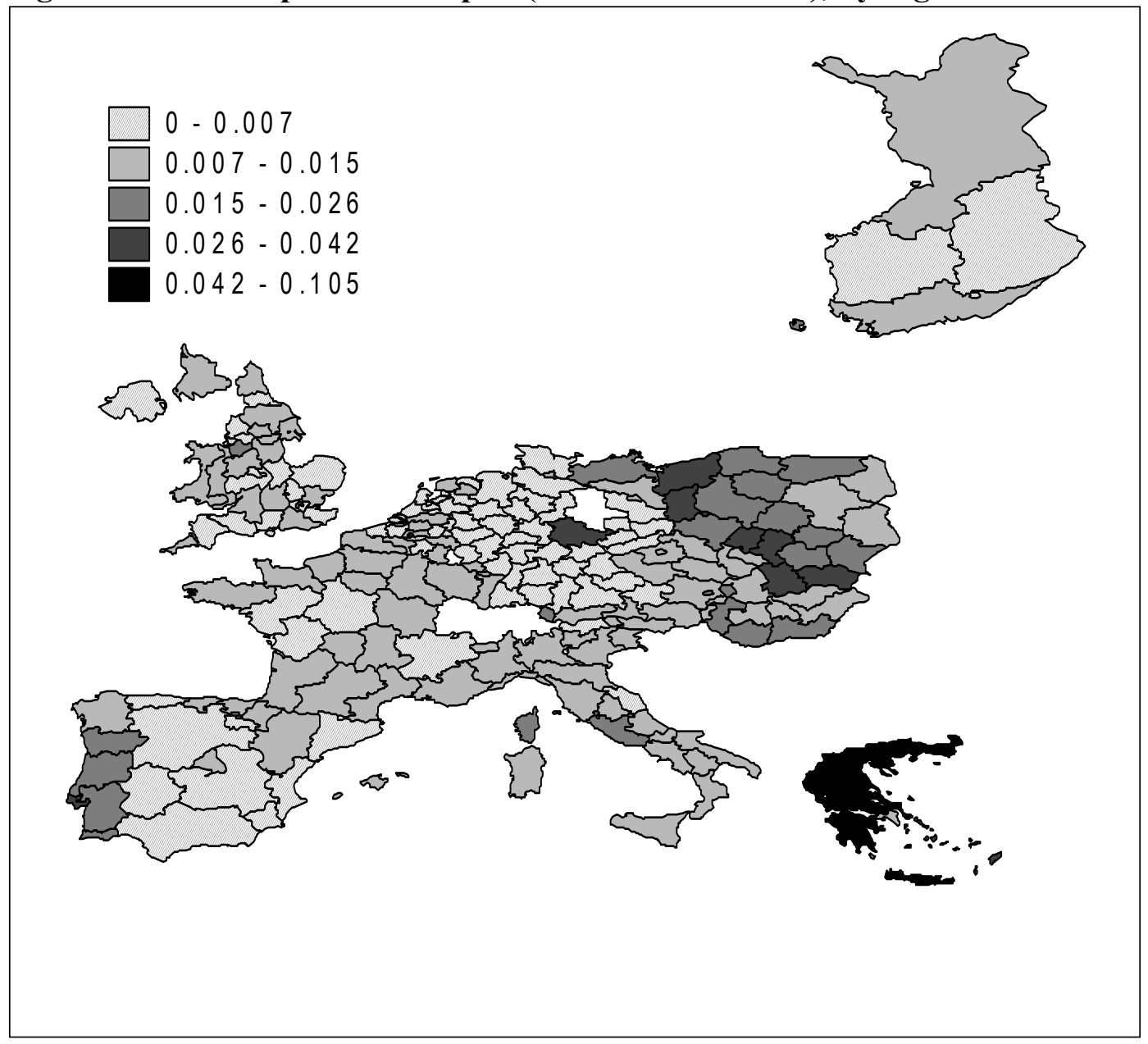


Table 1 - Correlation matrix

\begin{tabular}{|c|c|c|c|c|c|c|c|}
\hline & $\log \left(\alpha_{t} / \alpha_{t-1}\right)$ & $\log \left(\alpha_{t-1}\right)$ & $\log \left(\mathrm{w}_{\mathrm{t}-1} / \mathrm{w}_{\mathrm{t}-2}\right)$ & $\log \left[U_{t} /\left(E_{t}+U_{t}\right)\right]$ & $\log \left(\mathrm{TC}_{\mathrm{t}-1} / \mathrm{TC}_{\mathrm{t}-2}\right)$ & $\operatorname{og}\left(D_{t-1}\right)$ & $\log \left(S_{t-1}\right)$ \\
\hline $\log \left(\alpha_{t} / \alpha_{t-1}\right)$ & 1 & & & & & & \\
\hline $\log \left(\alpha_{t-1}\right)$ & -0.0978 & 1 & & & & & \\
\hline $\log \left(\mathrm{w}_{\mathrm{t}-1} / \mathrm{w}_{\mathrm{t}-2}\right)$ & -0.367 & 0.1319 & 1 & & & & \\
\hline $\log \left[U_{t} /\left(E_{t}+U_{t}\right)\right]$ & -0.06 & -0.1071 & -0.0015 & 1 & & & \\
\hline $\log \left(\mathrm{TC}_{\mathrm{t}-1} / \mathrm{TC}_{\mathrm{t}-2}\right)$ & 0.0482 & 0.038 & 0.0264 & -0.0385 & 1 & & \\
\hline $\log \left(D_{t-1}\right)$ & 0.1033 & -0.1989 & -0.0654 & -0.0472 & 0.0006 & 1 & \\
\hline $\log \left(S_{t-1}\right)$ & 0.0303 & 0.0435 & -0.0333 & -0.4709 & 0.0373 & -0.2981 & 1 \\
\hline
\end{tabular}


Table 2 - Fixed Effect Estimation of Equation (12)

\begin{tabular}{|c|c|c|c|c|}
\hline & (1) & $(2)$ & (3) & (4) \\
\hline Dep Var & $\log \left(\alpha_{t} / \alpha_{t-1}\right)$ & $\log \left(\alpha_{t} / \alpha_{t-1}\right)$ & $\log \left(\alpha_{t} / \alpha_{t-1}\right)$ & $\log \left(\alpha_{t} / \alpha_{t-1}\right)$ \\
\hline $\log \left(\alpha_{t-1}\right)$ & $\begin{array}{c}-.796 * * * \\
(.042)\end{array}$ & $\begin{array}{c}-.789 * * * \\
(.042)\end{array}$ & $\begin{array}{c}-.762 * * * \\
(.045)\end{array}$ & $\begin{array}{c}-.764 * * * \\
(.045)\end{array}$ \\
\hline $\log \left(w_{t-1} / w_{t-2}\right)$ & $\begin{array}{c}-.081 * * * \\
(.021)\end{array}$ & $\begin{array}{c}-.075 * * * \\
(.021)\end{array}$ & $\begin{array}{c}-.064 * * * \\
(.022)\end{array}$ & $\begin{array}{c}-.064 * * * \\
(.022)\end{array}$ \\
\hline $\log \left[U_{t} /\left(E_{t}+U_{t}\right)\right]$ & $\begin{array}{l}.007 * \\
(.005)\end{array}$ & $\begin{array}{l}.011 * * \\
(.005)\end{array}$ & $\begin{array}{l}.010 * * \\
(.005)\end{array}$ & $\begin{array}{l}.012 * * \\
(.005)\end{array}$ \\
\hline $\log \left(D_{t-1}\right)$ & & $\begin{array}{l}.160 * \\
(.087)\end{array}$ & & $\begin{array}{l}-.029 \\
(.019)\end{array}$ \\
\hline $\log \left(S_{t-1}\right)$ & & & $\begin{array}{c}-.036 * * \\
(.018)\end{array}$ & $\begin{array}{c}.116 \\
(.092)\end{array}$ \\
\hline Constant & $\begin{array}{c}-.572 * * * \\
(.033)\end{array}$ & $\begin{array}{c}-1.423 * * * \\
(.466)\end{array}$ & $\begin{array}{c}-.612 * * * \\
(.039)\end{array}$ & $\begin{array}{l}-1.224 \\
(.484)\end{array}$ \\
\hline Observations & 588 & 588 & 588 & 588 \\
\hline R-squared & 0.474 & 0.478 & 0.479 & 0.481 \\
\hline Number of id & 147 & 147 & 147 & 147 \\
\hline
\end{tabular}


Table 3 - Empirical Estimations of Equation (16) (Spatial Error Model)

\begin{tabular}{|c|c|c|c|c|}
\hline & (1) & (2) & (3) & (4) \\
\hline Dep Var & $\log \left(\alpha_{t} / \alpha_{t-1}\right)$ & $\log \left(\alpha_{t} / \alpha_{t-1}\right)$ & $\log \left(\alpha_{t} / \alpha_{t-1}\right)$ & $\log \left(\alpha_{t} / \alpha_{t-1}\right)$ \\
\hline $\log \left(\alpha_{t-1}\right)$ & $\begin{array}{c}-0.787 * * * \\
(-21.67)\end{array}$ & $\begin{array}{c}-0.789 * * * \\
-21.80)\end{array}$ & $\begin{array}{c}-0.750 * * * \\
(-19.47)\end{array}$ & $\begin{array}{c}-0.755 * * * \\
(-19.61)\end{array}$ \\
\hline $\log \left(w_{t-1} / w_{t-2}\right)$ & $\begin{array}{c}-0.095 * * * \\
(-5.154\end{array}$ & $\begin{array}{c}-0.092 * * * \\
(-5.045)\end{array}$ & $\begin{array}{c}-0.079 * * * \\
(-4.106)\end{array}$ & $\begin{array}{c}-0.078 * * * \\
(-4.10)\end{array}$ \\
\hline $\log \left[\mathrm{U}_{\mathrm{t}} /\left(\mathrm{E}_{\mathrm{t}}+\mathrm{U}_{\mathrm{t}}\right)\right]$ & $\begin{array}{l}0.009 * \\
(1.652)\end{array}$ & $\begin{array}{c}0.011 * * \\
(1.926)\end{array}$ & $\begin{array}{c}0.011 * * \\
(2.038)\end{array}$ & $\begin{array}{c}0.012 * * \\
(2.22)\end{array}$ \\
\hline $\log \left(D_{t-1}\right)$ & & $\begin{array}{c}0.183 * * \\
(2.210)\end{array}$ & & $\begin{array}{l}0.152 * \\
(1.83)\end{array}$ \\
\hline $\log \left(S_{t-1}\right)$ & & & $\begin{array}{c}-0.048 * * * \\
-2.745)\end{array}$ & $\begin{array}{c}-0.043 * * \\
(--2.44)\end{array}$ \\
\hline Spat. Aut. & $\begin{array}{l}-0.990 \\
(-1.46)\end{array}$ & $\begin{array}{l}-0.989 \\
(-1.46)\end{array}$ & $\begin{array}{l}-0.990 \\
(-1.47)\end{array}$ & $\begin{array}{l}-0.990 \\
(-1.46)\end{array}$ \\
\hline Observations & 588 & 588 & 588 & 588 \\
\hline R-squared & 0.587 & 0.591 & 0.592 & 0.594 \\
\hline Number of id & 147 & 147 & 147 & 147 \\
\hline
\end{tabular}


Table 4 - Emprical Estimations of Equation (15) (Spatial Autoregressive Model)

\begin{tabular}{|c|c|c|c|c|}
\hline & (1) & (2) & (3) & (4) \\
\hline Dep Var & $\log \left(\alpha_{t} / \alpha_{t-1}\right)$ & $\log \left(\alpha_{t} / \alpha_{t-1}\right)$ & $\log \left(\alpha_{t} / \alpha_{t-1}\right)$ & $\log \left(\alpha_{t} / \alpha_{t-1}\right)$ \\
\hline $\log \left(\alpha_{t-1}\right)$ & $\begin{array}{c}-0.770 * * * \\
(-20.57)\end{array}$ & $\begin{array}{c}-0.771 * * * \\
(-20.68)\end{array}$ & $\begin{array}{c}-0.742 * * * \\
(-19.00)\end{array}$ & $\begin{array}{c}-0.747 * * * \\
(-19.14)\end{array}$ \\
\hline $\log \left(w_{t-1} / w_{t-2}\right)$ & $\begin{array}{c}-0.074 * * * \\
(-3.75)\end{array}$ & $\begin{array}{c}-0.071 * * * \\
(-3.61)\end{array}$ & $\begin{array}{c}-0.064 * * * \\
(-3.19)\end{array}$ & $\begin{array}{c}-0.063 * * * \\
(-3.14)\end{array}$ \\
\hline $\log \left[\mathrm{U}_{\mathrm{t}} /\left(\mathrm{E}_{\mathrm{t}}+\mathrm{U}_{\mathrm{t}}\right)\right]$ & $\begin{array}{l}0.008 \\
(1.36)\end{array}$ & $\begin{array}{c}0.009 * \\
(1.60)\end{array}$ & $\begin{array}{c}0.010 * \\
(1.73)\end{array}$ & $\begin{array}{c}0.011 * * \\
(1.90)\end{array}$ \\
\hline $\log \left(D_{t-1}\right)$ & & $\begin{array}{c}0.191 * * \\
(2.31)\end{array}$ & & $\begin{array}{c}0.165 * * \\
(1.98)\end{array}$ \\
\hline $\log \left(S_{t-1}\right)$ & & & $\begin{array}{c}-0.042 * * \\
(-2.35)\end{array}$ & $\begin{array}{c}-0.036^{* *} \\
(-2.03)\end{array}$ \\
\hline $\mathrm{H}^{*}$ dep.var. & $\begin{array}{c}-0.870 * * * \\
(-2.70\end{array}$ & $\begin{array}{c}-0.901 * * * \\
(-2.82)\end{array}$ & $\begin{array}{c}-0.681 * * \\
(-2.13)\end{array}$ & $\begin{array}{c}-0.725 * * \\
(-2.68)\end{array}$ \\
\hline Observations & 588 & 588 & 588 & 588 \\
\hline R-squared & 0.593 & 0.597 & 0.596 & -2.27 \\
\hline Number of id & 147 & 147 & 147 & 147 \\
\hline
\end{tabular}


Table 5 - Fixed Effects estimation of Equation (13)

\begin{tabular}{|c|c|c|c|c|}
\hline & (1) & (2) & (3) & (4) \\
\hline Dep Var & $\log \left(M F P_{t} / M F P_{t-1}\right)$ & $\log \left(M F P_{t} / M F P_{t-1}\right)$ & $\log \left(M F P_{t} / M F P_{t-1}\right)$ & $\log \left(M F P_{t} / M F P_{t-1}\right)$ \\
\hline \multirow[t]{2}{*}{$\log \left(\mathrm{MFP}_{\mathrm{t}-1}\right)$} & $-.575 * * *$ & $-.598 * * *$ & $-.648 * * *$ & $-.640 * * *$ \\
\hline & $(.055)$ & $(.0537)$ & $(.055)$ & $(.055)$ \\
\hline \multirow[t]{2}{*}{$\log \left(\alpha_{t-1}\right)$} & $-.310 * *$ & $-.249 *$ & & \\
\hline & $(.160)$ & $(.156)$ & & \\
\hline \multirow[t]{2}{*}{$\log \left(\mathrm{TC}_{\mathrm{t}-1}\right)$} & & $.041 * * *$ & & $.028 * * *$ \\
\hline & & $(.009)$ & & $(.010)$ \\
\hline \multirow[t]{2}{*}{$\log \left(W_{t-1}\right)$} & & & $.214 * * *$ & $.155^{* * *}$ \\
\hline & & & $(.045)$ & $(.049)$ \\
\hline \multirow[t]{2}{*}{ Constant } & $1.315 * * *$ & $1.590 * * *$ & $1.042 * * *$ & $1.324 * * *$ \\
\hline & $(.153)$ & $(.161)$ & $(.158)$ & $(.187)$ \\
\hline Observations & 372 & 372 & 372 & 372 \\
\hline R-squared & 0.287 & 0.333 & 0.333 & 0.351 \\
\hline Number of id & 93 & 93 & 93 & 93 \\
\hline
\end{tabular}


Table 6 - Empirical estimations of Equation (18) (Spatial Error Model)

\begin{tabular}{|c|c|c|c|c|}
\hline & (1) & (2) & (3) & (4) \\
\hline Dep Var & $\log \left(M F P_{t} / M F P_{t-1}\right)$ & $\log \left(M F P_{t} / M F P_{t-1}\right)$ & $\log \left(M F P_{t} / M F P_{t-1}\right)$ & $\log \left(M F P_{t} / M F P_{t-1}\right)$ \\
\hline $\log \left(\mathrm{MFP}_{\mathrm{t}-1}\right)$ & $\begin{array}{c}-0.425^{* * *} \\
(-9.483)\end{array}$ & $\begin{array}{c}-0.469 * * * \\
(-10.33)\end{array}$ & $\begin{array}{c}-0.481 * * * \\
(-10.26)\end{array}$ & $\begin{array}{c}-0.532 * * * \\
(-11.20)\end{array}$ \\
\hline $\log \left(\alpha_{t-1}\right)$ & $\begin{array}{l}-0.226^{*} \\
(-1.70)\end{array}$ & $\begin{array}{l}-0.212 * \\
(-1.63)\end{array}$ & & \\
\hline $\log \left(\mathrm{TC}_{\mathrm{t}-1}\right)$ & & $\begin{array}{c}0.027 * * * \\
(3.86)\end{array}$ & & $\begin{array}{c}0.028 * * * \\
(4.10)\end{array}$ \\
\hline $\log \left(W_{t-1}\right)$ & & & $\begin{array}{c}0.144 * * * \\
(3.75)\end{array}$ & $\begin{array}{c}0.149 * * * \\
(3.97)\end{array}$ \\
\hline Spat. Aut. & $\begin{array}{l}-0.98 \\
(0.14)\end{array}$ & $\begin{array}{c}-0.99 \\
(-1.46)\end{array}$ & $\begin{array}{c}-0.99 \\
(-1.46)\end{array}$ & $\begin{array}{c}-0.98 \\
(-1.46)\end{array}$ \\
\hline Observations & 372 & 372 & 372 & 372 \\
\hline R-squared & 0.492 & 0.512 & 0.507 & 0.529 \\
\hline Number of id & 93 & 93 & 93 & 93 \\
\hline
\end{tabular}


Table 7 - Empirical estimations of Equation (17) (Spatial Autoregressive Model)

\begin{tabular}{|c|c|c|c|c|}
\hline & (1) & (2) & (3) & (4) \\
\hline Dep Var & $\log \left(M F P_{t} / M F P_{t-1}\right)$ & $\log \left(M F P_{t} / M F P_{t-1}\right)$ & $\log \left(M F P_{t} / M F P_{t-1}\right)$ & $\log \left(M F P_{t} / M F P_{t-1}\right)$ \\
\hline $\log \left(\mathrm{MFP}_{\mathrm{t}-1}\right)$ & $\begin{array}{c}-0.422 * * * \\
(-9.25)\end{array}$ & $\begin{array}{c}-0.467 * * * \\
(-10.05)\end{array}$ & $\begin{array}{c}-0.479 * * * \\
(-9.93)\end{array}$ & $\begin{array}{c}-0.531 * * * \\
(-10.77)\end{array}$ \\
\hline $\log \left(\alpha_{t-1}\right)$ & $\begin{array}{l}-0.23 * \\
(-1.74)\end{array}$ & $\begin{array}{l}-0.216^{*} \\
(-1.67)\end{array}$ & & \\
\hline $\log \left(\mathrm{TC}_{\mathrm{t}-1}\right)$ & & $\begin{array}{c}0.027 * * * \\
(3.92)\end{array}$ & & $\begin{array}{c}0.029 * * * \\
(4.17)\end{array}$ \\
\hline $\log \left(w_{t-1}\right)$ & & & $\begin{array}{c}0.146^{* * *} \\
(3.80)\end{array}$ & $\begin{array}{c}0.151 * * * \\
(4.02)\end{array}$ \\
\hline $\mathrm{H}^{*}$ dep.var. & $\begin{array}{c}-1.00 * * \\
(-2.35)\end{array}$ & $\begin{array}{c}-1.00 * * \\
(-2.40)\end{array}$ & $\begin{array}{c}-1.00 * * \\
(-2.43)\end{array}$ & $\begin{array}{c}-1.00 * * \\
(-2.50)\end{array}$ \\
\hline Observations & 372 & 372 & 372 & 372 \\
\hline R-squared & 0.509 & 0.528 & 0.524 & 0.545 \\
\hline Number of id & 93 & 93 & 93 & 93 \\
\hline
\end{tabular}

